\title{
Laserkrystaller
}

\section{- en klar fordel}

Af Jan Thøgersen, Kemisk Institut, Aarhus Universitet

\section{Et kig i krystalkuglen viser, at frem-} tiden for laserkrystaller i er lys. På verdens største lasermesse, Laser 2005, som netop er afholdt i München, kunne man forvisse sig om, at lasermarkedet er ved at blive overtaget af krystallaserne. Denne artikel beretter om krystallerne bag succesen.

I 1960 lykkedes det for første gang T. H. Maiman at frembringe laserlys. Laseren var baseret på en safirkrystal $\left(\mathrm{Al}_{2} \mathrm{O}_{3}\right)$ doteret med $\mathrm{Cr}^{3+}$ kromioner (rubin) og udsendte sit karakteristiske røde lys som en række kraftige lyspulser i en meget veldefineret stråle, som vi senere har lært at kende som en laserstråle. Siden opfindelsen af rubinlaseren har krystaller doteret med ioner af forskellige grundstoffer været under konstant udvikling, og krystallerne indtager i disse år en klar førerposition, når det gælder produktionen af nye lasertyper.

Krystallernes succes skyldes først og fremmest, at de kan lagre endog meget høje energitætheder og derved producere kraftige laserstråler fra et relativt lille volumen. Derfor kan krystallasere gøres meget kompakte og robuste, som for eksempel i laserpegepinden (foto side 8). Under normal drift er der ingen slitage på laserkrystallerne og $\mathrm{i}$ forhold til andre lasermedier som gas og farvestoffer har krystallerne en næsten uendelig levetid, selv uden vedligehold. Den sideløbende udvikling af effektive halvleder diodelasere til optisk pumpning af krystal-

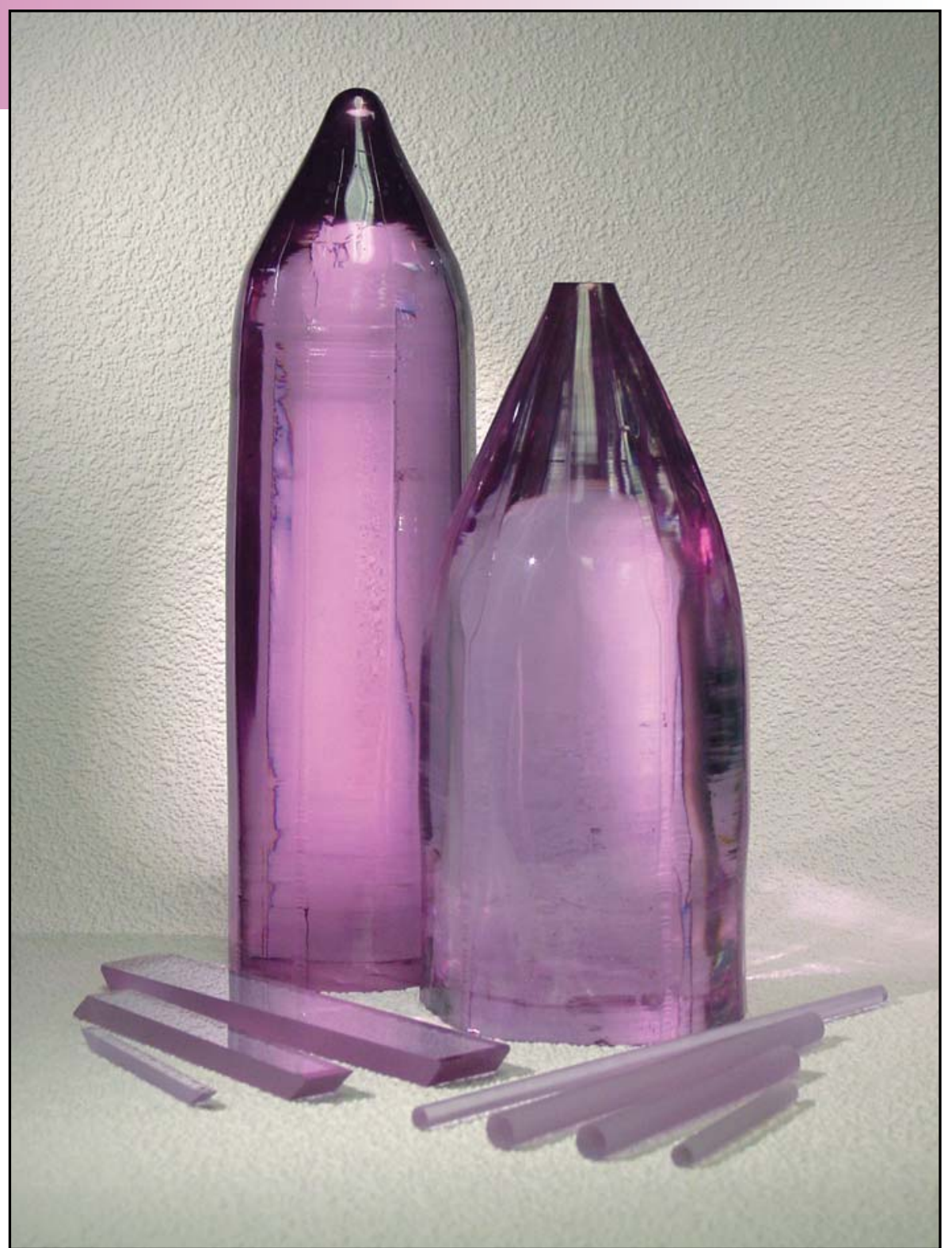

$N d^{3+}: Y A G$ krystalbouler (de to store krystaller) og fardigpolerede laserkrystaller. (Fotos venligst udlånt af Northrop Grumman Directed Energy Systems - SYNOPTICS via www.st.northropgrumman.com/synoptics)

lerne har muliggjort strøm til lys effektivitet på op imod $20 \%$. Det er derfor ikke så sært, at krystallaserne på det nærmeste har

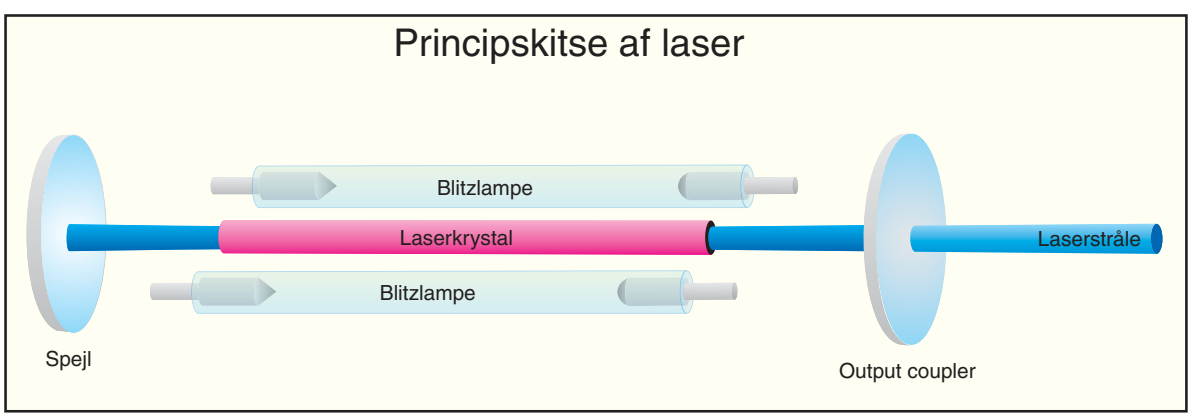

Principskitsen af en laser viser hvordan lys fra to blitzlamper anslär det laseraktive medium. Stimuleret udsendelse af lys fra mediet reflekteres tilbage gennem lasermediet af to spejle og bliver derved yderligere forstcerket. Reflektiviteten af det ene spejl (output coupler) er per design mindre end 100 $\%$, og det transmitterede lys udsendes $i$ en laserstråle. (Grafik:Forfatteren) udkonkurreret tidligere så populære lasertyper som for eksempel argon-ion og kobberdampslasere.

I det følgende skal vi se, hvad der gør doterede krystaller så velegnede som lasermedium, men først en kort gennemgang af laserens opbygning og virkemåde.

\section{En laserskitse}

Som skitseret på figuren til venstre består en laser i princippet af en energikilde, et lasermedium og en optisk resonator. Energikilden er ofte en blitzlampe eller en anden laser, hvis lys tilfører energi til lasermediet. Lasermediet kan for eksempel være en atomar gas, et farvestof, en halvleder eller en krystal doteret med atomare ioner. Fælles for alle lasermedier er dog, at der blandt deres talrige energiniveauer findes mindst tre og 


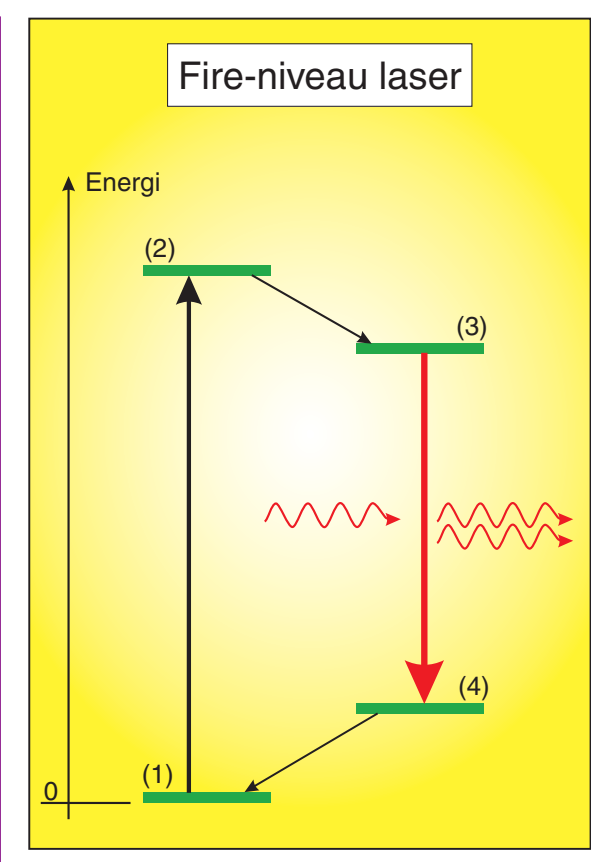

helst fire, der opfylder en række betingelser, som vi skal nu skal se på.

Lad os betragte fire-niveau laseren skitseret i figuren ovenfor. I en laser med fire aktive energiniveauer absorberer atomerne i lasermediet energi fra den eksterne energikilde og bliver derved flyttet fra grundtilstandens energiniveau (1) op i et anslået niveau (2). Fra dette niveau henfalder atomerne spontant til et niveau med lavere energi (3) for eksempel ved udsendelse af lys. Niveau (3) udgør det øvre laserniveau. Hvis atomerne i niveau (3) vekselvirker med lys med en energi svarende til energiforskellen mellem niveauerne (3) og (4), stimuleres henfaldet til niveau (4). Under denne proces udsender atomet lys med samme energi, retning og fase som det lys, det vekselvirker med. Det udsendte lys interferer konstruktivt med det indkommende og herved forstærkes lyset. Det er derfor energiopsplitningen, $\Delta \mathrm{E}$, mellem det øvre og nedre laserniveau, der bestemmer laserens bølgelængde, $\lambda$, og dermed farve i henhold tilformlen:

$\lambda=\mathrm{hc} / \Delta \mathrm{E}$,

hvor h er Plancks konstant og c lysets hastighed. Efter det stimulerede henfald befinder atomerne sig i niveau (4), som er det nedre laserniveau. Herfra henfalder atomerne hurtigt tilbage til grundtilstandens energiniveau (1), så de kan bruges i en ny forstærkningscyklus.

Eftersom stimuleret absorption af lys og deraf følgende overførsel af atomer fra niveau (4) til niveau (3) er lige så sandsynlig som stimuleret henfald fra niveau (3) til niveau (4), er det afgørende for forstærkningsprocessen, at der altid er flere atomer $i$ det Øvre end i det nedre laserniveau. Dette kan normalt ikke opfyldes af et to-niveau system, men kræver mindst tre og helst fire
Skitsen af $\mathrm{Nd}^{3+}: Y A G$ laserens energiniveauer viser, hvordan lys fra en ydre kilde anslår højtbeliggende niveauer $i \mathrm{Nd}^{3+}$. $\mathrm{Nd}^{3+}$ ionerne $i$ disse niveauer henfalder til det øvre laserniveau under afgivelse af overskudsenergien til $Y A G$ krystallens gittersvingninger. Stimuleret henfald mellem niveauerne (3) og (4) resulterer $i \mathrm{Nd}^{3+}:$ YAG laserens karakteristiske laserlys ved $1.064 \mathrm{~nm} . \mathrm{Nd}^{3+}$ ionerne i niveau (4) afgiver resten af deres overskudsenergi til vartskrystallen og kommer derved tilbage til grundtilstandsniveauet. (Grafik: Forfatteren)

Fire-niveau lasersystem. Lasermediet absorberer lys fra en ydre kilde og bliver derved anslået fra grundtilstandsniveauet (1) til niveau (2). Hurtigt henfald fra niveau (2) befolker det øvre laserniveau (3). Laserlyset opstår som følge af stimuleret henfald mellem niveauerne (3) og (4). Hurtigt tømning af niveau (4) bringer lasermediet tilbage til grundtilstanden, som derved er klart til endnu en rundtur. (Grafik: Forfatteren)

niveauer, hvor sandsynligheden for spontane henfald fra niveau (2) til niveau (3) og fra niveau (4) til niveau (1) er stor, samtidig med at sandsynligheden for et spontant henfald fra det øvre til det nedre laserniveau er meget lille.

Det laseraktive medium placeres i en optisk resonator i princippet bestående af to spejle, der reflekterer det forstærkede lys gennem lasermediet gentagne gange. Resonatoren har til formål at forlænge den effektive længde af lasermediet og dermed forøge forstærkningen samt at udvælge netop de frekvenser fra det forstærkede lys,

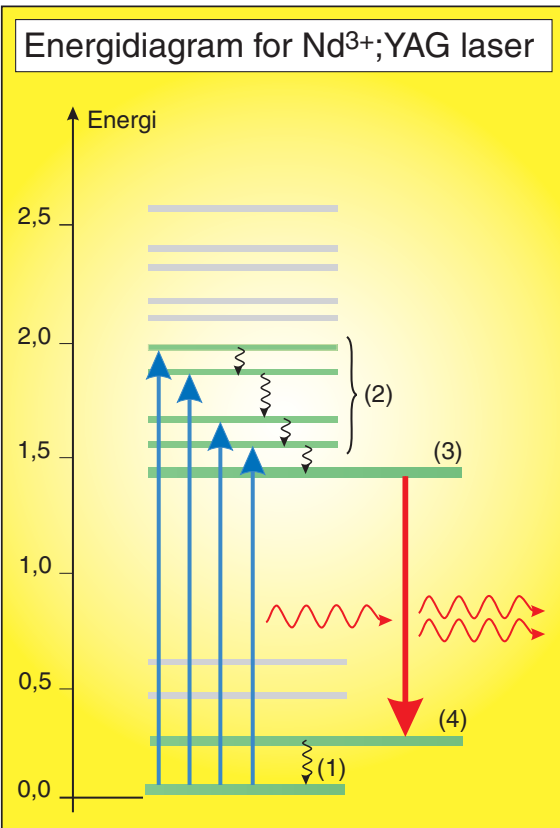

der efter en rundtur i resonatoren svinger $i$ fase med lyset fra forrige rundtur, dvs. opfylder resonatorbetingelsen. Det er således i høj grad resonatoren, der giver laserstrålen sin veldefinerede bølgelængde og retning.

Igennem de 45 år, der er gået siden opfindelsem af laseren, er det lykkedes at få hundredevis af forskellige krystaller til at udsende laserlys. I modsætning til rubinlaseren, som i princippet kunne være baseret på en naturligt forekommende rubin, er alle øvrige krystallasere lavet af syntetisk fremstillede krystaller. Her vil vi blot gennemgå tre af de mest almindelige.

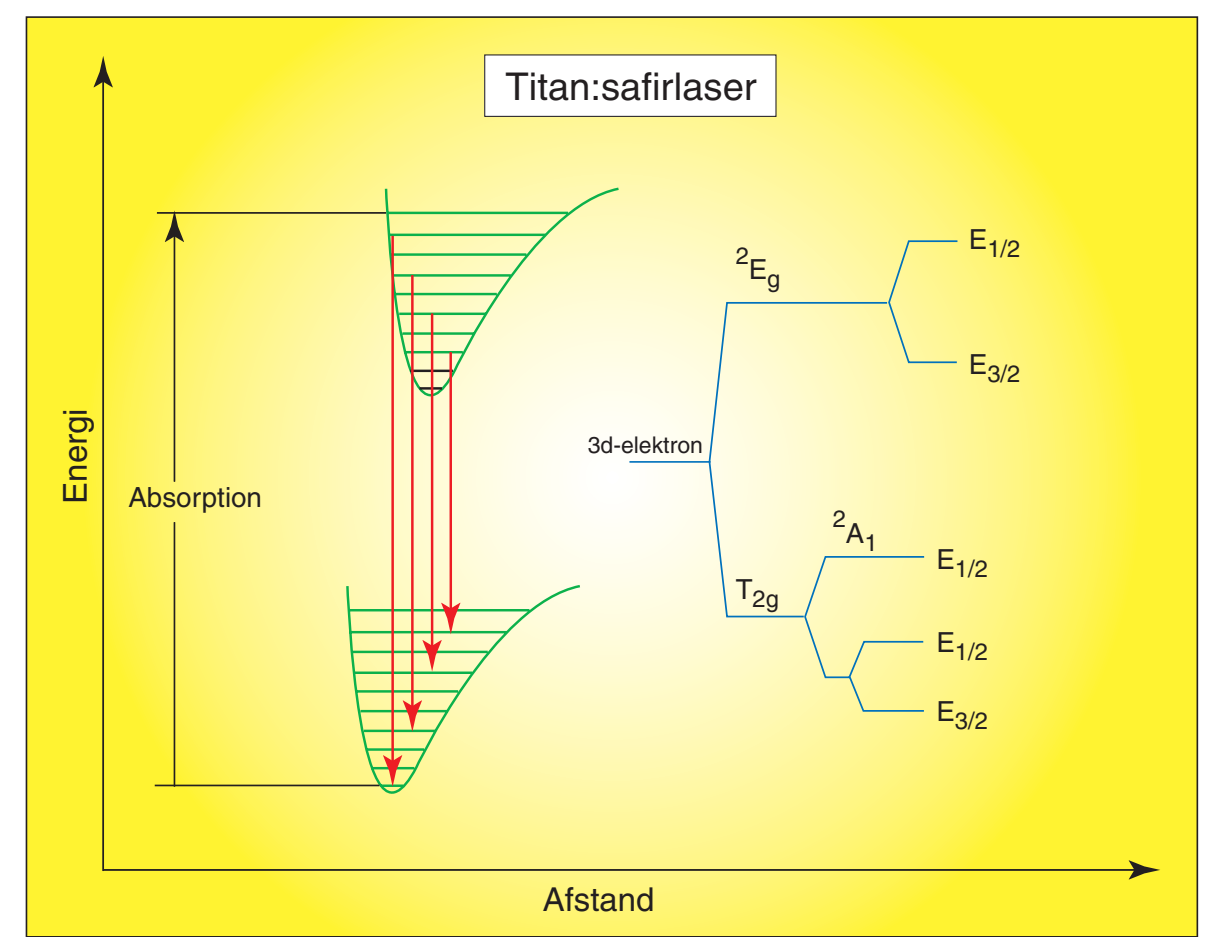

Skitse af energiniveaudiagram for $T^{3+}$ : safirlaseren. Krystalfeltet giver en kraftig opsplitning af $3 d$ elektronens energiniveauer, som igen forbreddes ved vekselvirkning med krystalgitterets vibrationer og resulterer i titansafirens brede spektralområde. (Grafik: Forfatteren) 


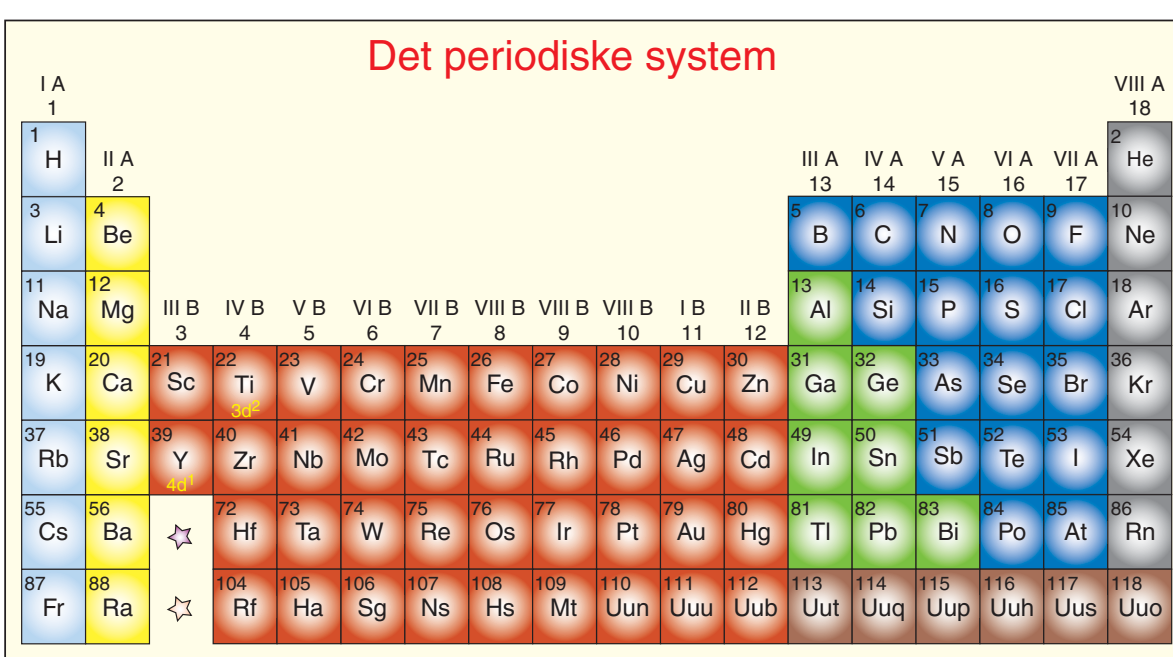

Sjældne jordarter

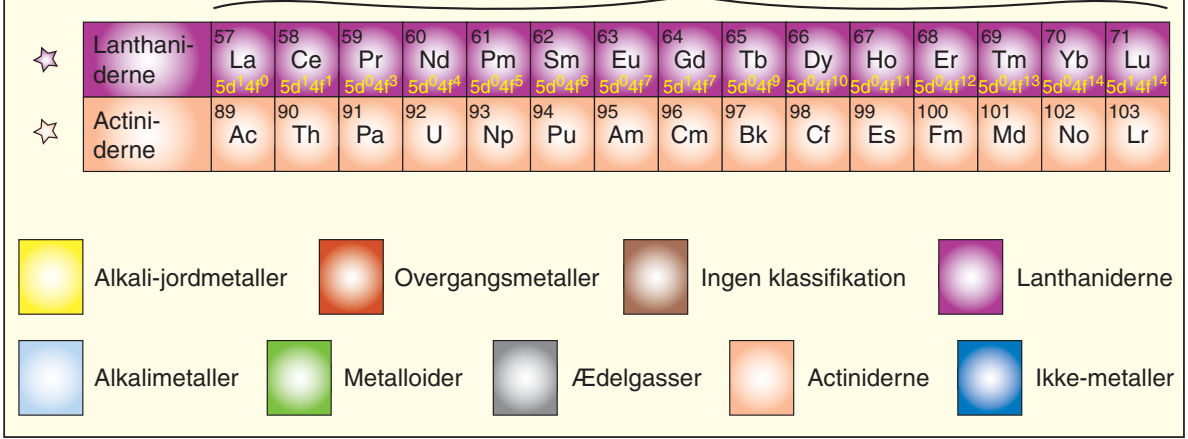

Det periodiske system. Lag sarligt marke til elektron-konfigurationerne af de sjaldne jordarter og titan. Ved de trivalente sjaldne jordarter forsvinder en f-elektron og de to 6 s elektroner, men den laseraktive f-elektron er stadig delvist skarmet mod vartskrystallens ligandfelt af $5 s^{2}$ og $5 p^{6}$ elektroner. Således er konfigurationen af neutralt $\mathrm{Nd}[\mathrm{Xe}] 4 f^{4} 6 \mathrm{~s}^{2}$, mens den for $\mathrm{Nd}^{3+}$ er $[\mathrm{Xe}] 4 f^{3}$. Derimod er $\mathrm{Ti}^{3+}$ 's $3 d$ elektron ikke skcrmet og morker i højere grad det elektriske felt fra krystallen. (Grafik: UVH)

\section{$\mathrm{Nd}^{3+}$ :YAG krystallen}

Den mest udbredte krystalbaserede laser er uden sammenligning neodymium:yttrium aluminium granat, $\mathrm{Nd}^{3+}: \mathrm{Y}_{3} \mathrm{Al}_{5} \mathrm{O}_{12},(\mathrm{Nd}: \mathrm{YAG})$ laseren, og den er samtidig et godt eksempel på en fire-niveau laser. Neodymium erstatter typisk $1 \%$ af yttrium-atomerne i YAG gitteret og sidder som trivalente $\mathrm{Nd}^{3+}$ ioner omgivet af aluminium- og iltatomer som vist 1 boksen på modstående side.

Energiniveaudiagrammet øverst til højre foregående side viser $\mathrm{Nd}^{3+}$ 's grundtilstandsniveau og talrige anslåede niveauer. $\mathrm{Nd}^{3+}$ ionerne absorberer i et bredt område i den

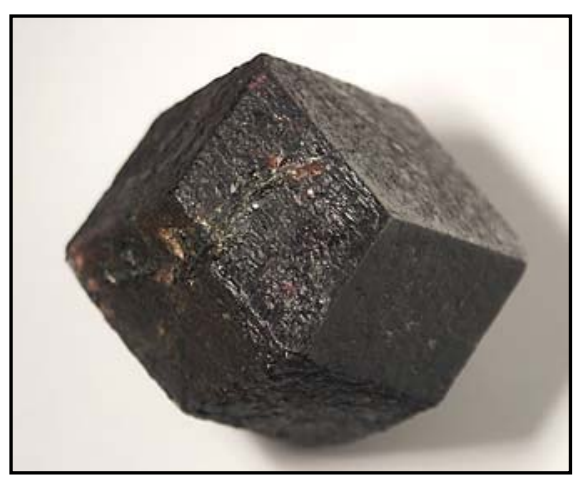

Almandingranat som de findes i naturen. (Foto: Morten L. Hjuler) gul-grønne del af det synlige spektrum svarende til overgange mellem grundtilstanden og niveauerne omkring 2-3 eV. Det giver Nd:YAG krystallen sin karakteristiske lyserøde farve (se fotos i boksen på modstående side). Endvidere absorberer $\mathrm{Nd}^{3+}$ ionerne $\mathrm{i}$ den nær-infrarøde del af spektret, hvilket gørNd:YAG velegnet til optisk pumpning med xenon-eller krypton-blitzlamper, som netop udsender lys i dette område. Lyset fra blitzlamperne anslår niveauerne over det øvre laserniveau (3), som i løbet af nanosekunder henfalder til niveau (3). Henfaldet sker trinvis gennem lavereliggende niveauer, ikke ved udsendelse af lys, da sandsynligheden for optiske overgange mellem disse niveauer er lille, men derimod ved en meget effektiv energioverførsel til YAG krystallens gittersvingninger (phononer). Ved denne form for energiafgivelse vokser henfaldstiden af de anslåede niveauer i $\mathrm{Nd}^{3+}$ ionerne eksponentielt med energiforskellen til ionernes naboniveauer og bliver derfor meget lang $(0,25 \mathrm{~ms})$, når $\mathrm{Nd}^{3+}$ ionerne ankommer til det øvre laserniveau (3). Kravet om en hurtig og effektiv befolkning af det øvre laserniveau opfyldes således elegant af værtskrystallen.

Laserovergangen sker ved stimuleret henfald mellem niveau (3) og (4), som har en energiforskel på $1,17 \mathrm{eV}, \mathrm{og} \mathrm{Nd}$ :YAG laseren lyser derfor infrarødt med en bølgelængde på $1.064 \mathrm{~nm}$. Fra det nedre laserniveau (4) afgiver $\mathrm{Nd}^{3+}$ ionerne hurtigt deres overskudsenergi til krystalgitteret og kommer derved tilbage til grundtilstandsniveauet.

\section{Ligandfelt justerer laserbølgelængden} Den effektive energioverførsel mellem ion og værtskrystal er tydeligvis helt afgørende for Nd:YAG laseren. Men det er ikke den eneste funktion af krystallen. Den nøjagtige energi af $\mathrm{Nd}^{3+}$ ionernes niveauer afhænger nemlig i nogen grad af det lokale elektriske felt, også kaldet ligandfeltet, som $\mathrm{Nd}^{3+}$ ionerne føler i YAG krystallen. Derfor kan niveauernes energi justeres ved at skifte til en anden værtskrystal.

Benyttes således en yttrium lithium fluorid, $\mathrm{YLF}_{4}$, (YLF) krystal i stedet for YAG, bliver energigabet mellem de to laserniveauer større, og laserens bølgelængde skifter følgelig fra $1.064 \mathrm{~nm}$ til $1.053 \mathrm{~nm}$. Nd ${ }^{3+}$ ionerne har været benyttet i mere end 100 forskellige værtskrystaller, som tilsammen dækker et spektralområde fra $1.041 \mathrm{~nm}$ til $1.116 \mathrm{~nm}$. Det er dog de færreste af disse værtskrystaller, hvis mekaniske og optiske egenskaber har tilladt en kommerciel udnyttelse. Nd:YAG laseren udgør blot et enkelt medlem i familien af lasere, der benytter krystaller doteret med grundstoffer fra gruppen af sjældne jordarter som lasermedium (figuren ovenfor). Listen omfatter mere end tusinde forskellige krystaller, som tilsammen dækker et spektralområde fra $\mathrm{Ce}^{3+}$ :YLF's nær-ultra-

\section{Fourierteori}

\section{Sammenhæng mellem pulslængde og spektralbredde}

Vi tænker som regel på laserlys som en stråle med en meget veldefineret bølgelængde eller farve. Men sådan er det faktisk ikke altid. Som et resultat af Fourierteori har produktet mellem varigheden af en laserpuls, $\Delta \mathrm{t}$, og dens spektrale bredde, $\Delta v$, en nedre grænse større end nul. For en puls med gaussisk form er den nedre græn- se for dette produkt således $\Delta \mathrm{v} \Delta \mathrm{t}>0,42$. Det har en række overraskende og vigtige konsekvenser. Skal man således lave en laser med en meget velbestemt frekvens (lille $\Delta v$ ), skal man lade laseren lyse i lang tid (stor $\Delta \mathrm{t}$ ). Omvendt skal en laser, der udsender meget korte pulser (lille $\Delta \mathrm{t}$ ), have et meget bredt spektrum (stor $\Delta v$ ). 


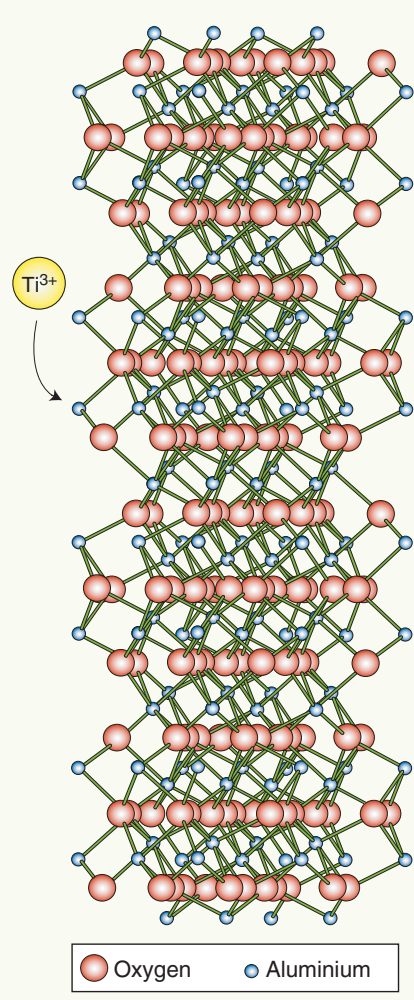

\section{Korund (safir)}

I titan:safir $\left(\mathrm{Ti}^{3+}: \mathrm{Al}_{2} \mathrm{O}_{3}\right)$ krystaller erstattes ca. $0,1-1 \%$ af aluminiumatomerne med $\mathrm{Ti}^{3+}$ ioner. Placeringen af $\mathrm{Ti}^{3+} \mathrm{i} \mathrm{Al}_{2} \mathrm{O}_{3}$ har trigonal symmetri. Krystalfeltet resulterer i en kraftig opsplitning og forbredning af $\mathrm{Ti}^{3+}$ ionens energiniveauer og tillader titan:safir krystallen at lyse $\mathrm{i}$ et bredt spektrum i intervallet $660-1.050 \mathrm{~nm}$. Den store spektralbredde gør titansafirlaseren til en af de mest foretrukne kilder til laserspektroskopi. Værtskrystallens styrke bevirker, at laserkrystallen kan tåle endog meget høje laserintensiteter.

I en anden safir, nemlig rubin $\left(\mathrm{Cr}^{3+}: \mathrm{Al}_{2} \mathrm{O}_{3}\right)$, erstatter $\mathrm{Cr}^{3+}$ ca. $0,05 \%$ af aluminiumatomerne. Rubinlaseren laser $i$ to snævre bølgelængdeområder ved $628 \mathrm{~nm}$ og $694 \mathrm{~nm}$.

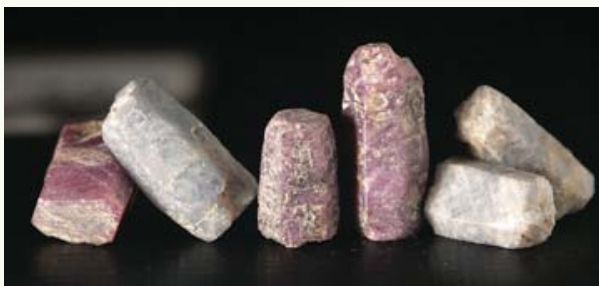

Naturligt forekommende safirer (blå) og rubiner (røde). (Foto: Morten L. Hjuler)

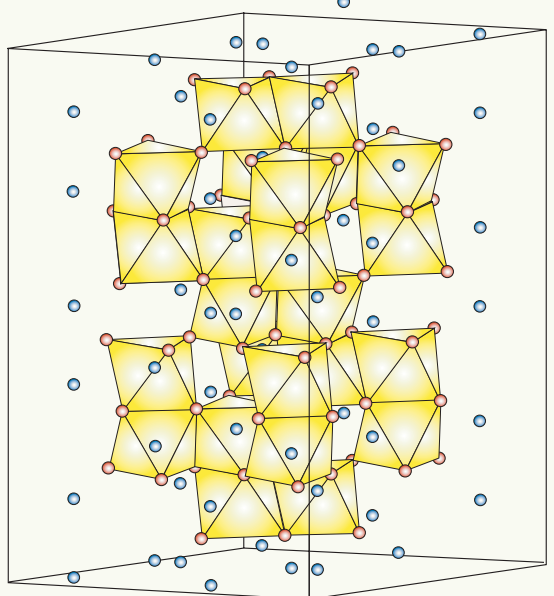

$\circ$ Oxygen $\circ$ Aluminium

I figuren ovenfor demonstreres det, hvordan Al-O oktaedrerne er forbundet igennem den trigonale krystal. Figuren til venstre viser et større udsnit af oktaederbindinger. (UVH modificeret efter forlæg af Svend Erik Rasmussen)

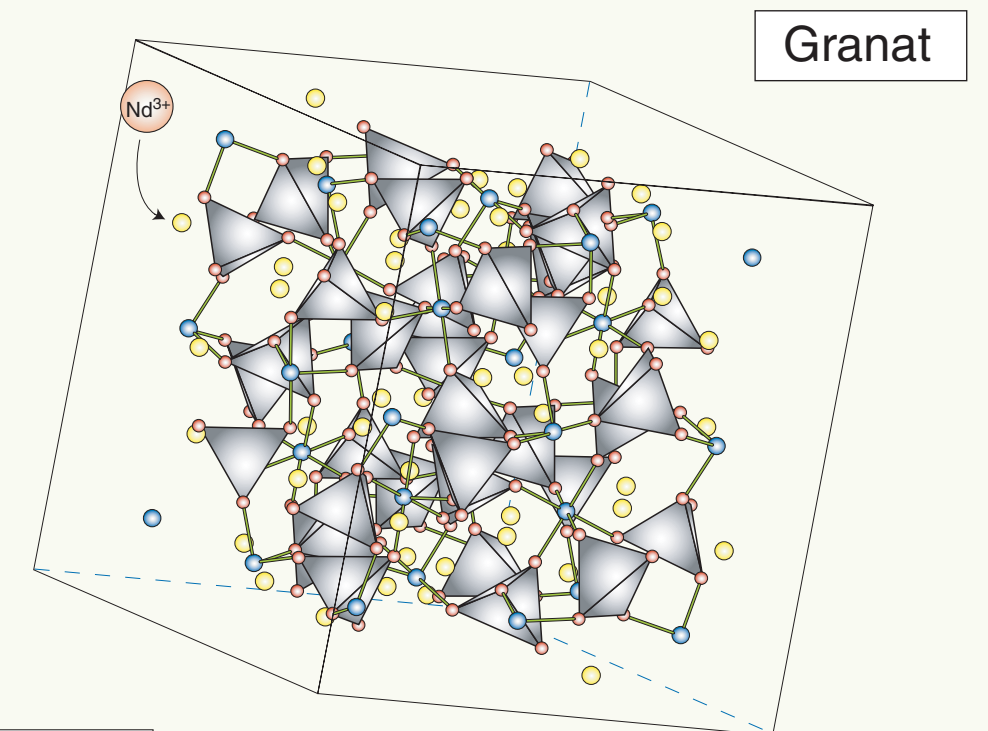

I neodymium yttrium aluminium granat laseren erstatter $\mathrm{Nd}^{3+}$ ionerne de otte-koordinerede $\mathrm{Y}^{3+}$ ioner. Koncentrationen af neodymiumatomer udgør typisk $1 \%$. Højere koncentrationer vanskeliggøres af den $11 \%$ større ionradius af neodymiumionen og resulterer i krystaldefekter.

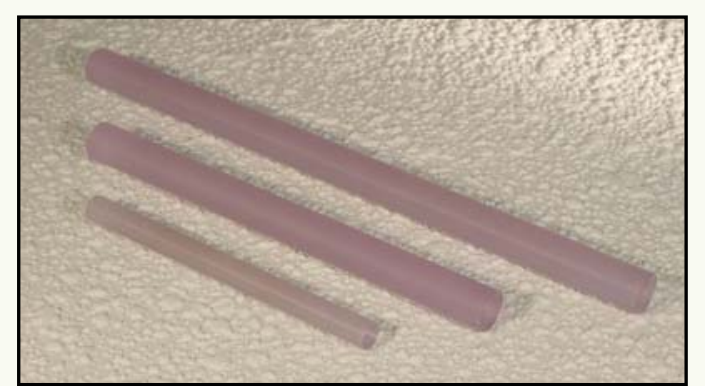

Laserstænger skåret af syntetisk fremstillet $\mathrm{Nd}^{3+}:$ YAG. (Fotos venligst udlånt af Northrop Grumman Directed Energy Systems)

Denne afbildning af den kubiske granat viser Al-O tetraedrene med farven sort Aluminium samt aluminiumatomer angivet med blå farve. Disse Al-atomer er bundet til seks Yttrium oxygenatomer. Yttriumatomerne er angivet med gul, men bindingerne til oxygen er udeladt. (UVH modificeret efter forlæg af Svend Erik Rasmussen)

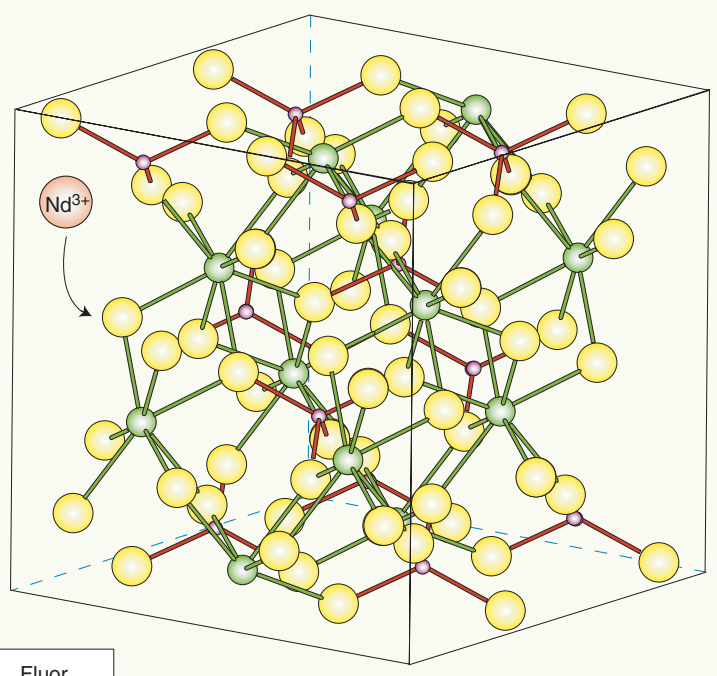

Fluor

Lithium Yttrium

\section{Fluorid}

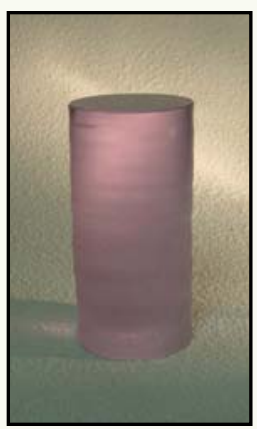

$\mathrm{Nd}^{3+}: \mathrm{YLF}_{4}$ Boule og laserstænger skåret fra boulen. (Fotos venligst udlånt af Northrop Grumman Directed Energy Systems) krystalenderne uden refleksionstab.
Krystallerne vokser ud fra en kim-krystal vha. Czochralskimetoden. Den færdige krystal-boule er typisk $25 \mathrm{~cm}$ lang og $10 \mathrm{~cm}$ i diameter. Fra boulen udskæres cylindriske stænger med en diameter på $4-10 \mathrm{~mm}$. Enderne på stængerne slibes helt parallelle og så plane, at ujævnheder på overfladen højst er 1/10 af laserens bølgelængde. Til sidst pådampes en anti-refleks film på enderne, således at laserlyset på sin vej frem og tilbage mellem spejlene kan passere igennem

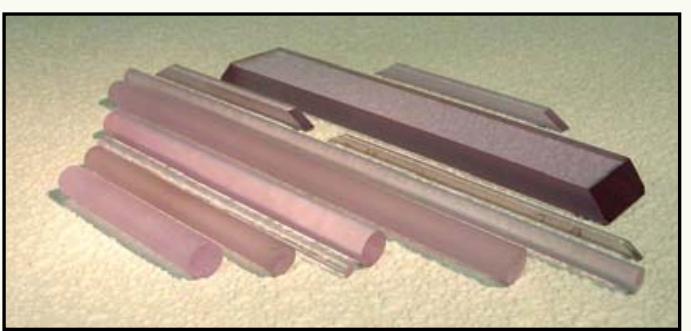

Som i yttrium aluminium granat erstattes ca. $1 \%$ af $\mathrm{Y}^{3+}$ ionerne $\mathrm{iYLF}_{4}$ af $\mathrm{Nd}^{3+}$ ioner. I forhold til YAG udmærker $\mathrm{YLF}_{4}$ sig ved en lav termisk linseeffekt, hvilket forbedrer laserstrålens kvalitet og letter designet af laserkaviteter i lasere med høj effekt. 


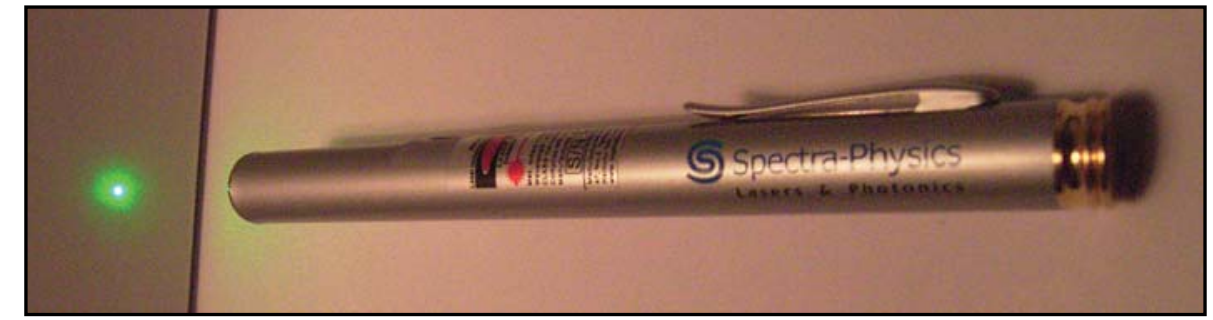

Grøn laserpegepind baseret på neodymium-doteret yttrium vanadat $\left(\mathrm{Nd}^{3+}: \mathrm{YVO}_{4}\right)$. Laserens infraføde lys frekvensfordobles efterfølgende $i$ en ikke-linear krystal for at opnå den grønne stråle. (Foto: Forfatteren)

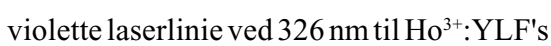
midtinfrarøde laser ved $3.914 \mathrm{~nm}$. Et udvalg af synlige og nær-infrarøde laserlinier er angivet i figuren til højre.

\section{Titan:safir - en spektroskopikers drøm}

På trods af de mange fortræffelige egenskaber er laserne baseret på krystaller doteret med sjældne jordarter begrænset af, at de kun kan lyse i et snævert spektralområde på få nanometer. Det skyldes, at de sjældne jordarters $5 s^{2}$ og $5 p^{6}$ elektroner i nogen grad skærmer den laseraktive 4 f elektron fra krystalfeltet, og 4f elektronen bevarer derved de relativt skarpe energiniveauer.

I mange anvendelser er det imidlertid ønskeligt, at laserens bølgelængde kan justeres over et meget bredt spektralområde. Denne egenskab findes for eksempel hos den trivalente $\mathrm{Ti}^{3+}$ ion. I modsætning til de sjældne jordarters skærmede 4 f elektron, føler $\mathrm{Ti}^{3+}$ ionens laseraktive $3 \mathrm{~d}$ elektron $\mathrm{i}$ meget højere grad det lokale elektriske felt $i$ værtskrystallen. Sidder $\mathrm{Ti}^{3+}$ ionerne for eksempel i en safirkrystal, $\mathrm{Al}_{2} \mathrm{O}_{3}$, resulterer ligandfeltet $i$ en kraftig opsplitning af de snævre atomare niveauer. Opsplitningen af 3 d elektronens energiniveauer er vist på figuren nederst på side 5. Da safirkrystallens lokale elektriske felt tilmed blander $\mathrm{Ti}^{3+}$ ionernes elektroniske niveauer med gittersvingningernes vibrationsenergier forbreddes de enkelte niveauer i en sådan grad, at de overlapper. Derved bliver det muligt at variere titan:safir laserens bølgelængde kontinuert i intervallet $660-1050 \mathrm{~nm}$, altså med ca. $400 \mathrm{~nm}$. Med dens brede spektralområde er titan:safir laseren i dag den absolut mest udbredte krystalbaserede laser til spektroskopi.

\section{De korteste laserpulser nogensinde} Størst indflydelse har den titandoterede safirkrystal dog haft for udviklingen af pulserede lasere. Nærmere betegnet femtosekundlasere, der udsender deres laserstråle i form af lyspulser med en varighed på 100 femtosekunder eller mindre ( $\left.1 \mathrm{fs}=10^{-15} \mathrm{~s}\right)$.

Resultater fra matematikkens fourierteori medfører, at for at en laser kan producere så korte laserpulser, skal dens aktive medium kunne forstærke et meget bredt spektrum af laserbølgelængder. Som forklaret ovenfor behersker den titandoterede safirkrystal denne egenskab bedre end nogen anden. Netop titansafirkrystallens potentiale for at lave korte laserpulser er siden sin opdagelse i 1980'erne blevet presset til grænsen, og de korteste optiske laserpulser til dato er således lavet af titansafirlasere. Laserpulserne har en varighed på mindre end $5 \mathrm{fs}$ svarende til blot to svingninger af laserlyset! Som følge af fourier-teori dækker de korte laserpulser et spektrum på mere end $300 \mathrm{~nm}$. Det står i skærende kontrast til den meget snævre spektralbredde af kontinuerte lasere. Havde titan:safirlaserens centerbølgelængde således været grøn (ca. $500 \mathrm{~nm})$ i stedet for nærinfrarød $(800 \mathrm{~nm})$, ville laserlyset være hvidt!

\section{Enorme effekter}

Med den korte pulslængde er det blevet muligt for titan:safir lasersystemer at producere fantastiske lysstyrker. Således findes der nu verden over flere lasersystemer med pulseffekter på over en $1 \mathrm{PW}\left(\right.$ PetaWatt $=10^{15}$ W) svarende til effekten af ca. 1 million middelstore danske kraftværker eller 1.000 gange USA's samlede el-kapacitet. I de kommende år vil denne udvikling med sikkerhed fortsætte. De enormt effektfulde lasere finder anvendelse fra studier af vekselvirkning mellem lys og elementarpartikler til antændelse af fusionsplasma i fusionsreaktorer - og det er alt sammen muliggjort af krystaller doteret med atomare ioner.

\section{Litteratur}

A. A. Kaminskii, Laser Crystals 2nd edition. Springer Series in Optical Sciences Vol. 141990.

P. F. Moulton, J. Opt. Soc. Am. B, p. 125133, vol.3 1986.

Tak til:

Prof. emeritus Svend Erik Rasmussen, Geologisk Institut, Aarhus Univeristet for illustrationer af krystalstrukturerne samt Ulf Kapborg, Northrop Grumman for hjcelp med fotos af laserkrystaller.

Udvalgte laserlinier fra krystaller doteret med sjeldne jordarter samt krom og titan. (Grafik: $U V H)$

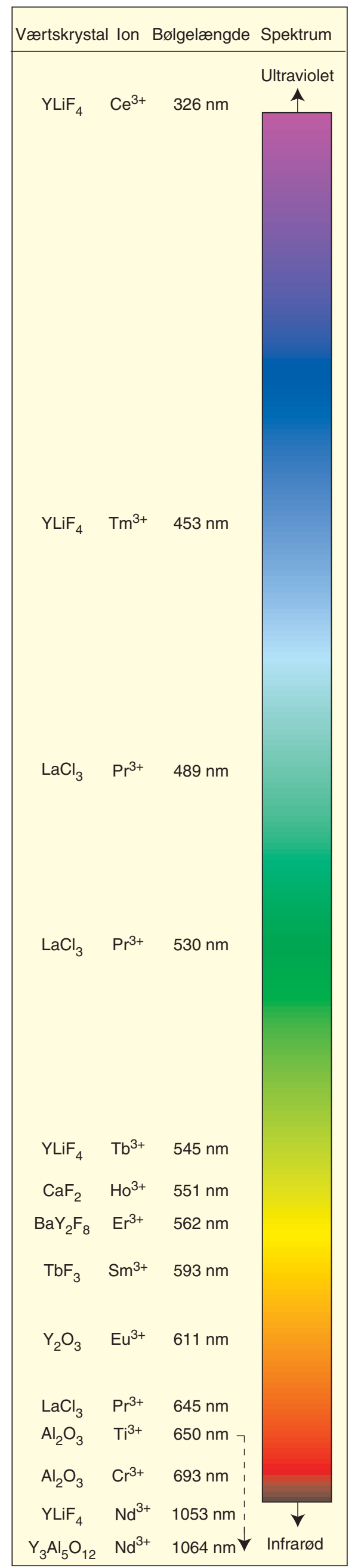

